\title{
7. A Mysterious Man, who Has No Classifiable Papillar Ridge Pattern on Fingers and Toes.
}

By Tanemoto Furuhata, M.J.A., and Naoki Kuwashima. Institute of Legal Medicine, Medical Faculty, University of Tokyo.

(Comm. Feb. 13, 1950.)

In June 1949 it was found by chance that a policeman named Tatsuo Takeshita, 22 years old and working at a police station in Hamamatsu city of Shizuoka Prefecture, had no classifiable papillar ridge pattern on all his fingers and toes. His mother Chiyo Takeshita, 45 years old and living in Kamiuchida mura, Ogasa Gun, Shizuoka Prefecture, also has no finger tip pattern. It is said that Chiyo's father Sahei had likewise no finger pattern, but the truth thereof cannot be clarified as he is already dead. Tatsuo's sister Chieko (34 years old), brother Kosuke (25 years old) and sister Yukiko (18 years old) have all finger papillar pattern as an ordinary

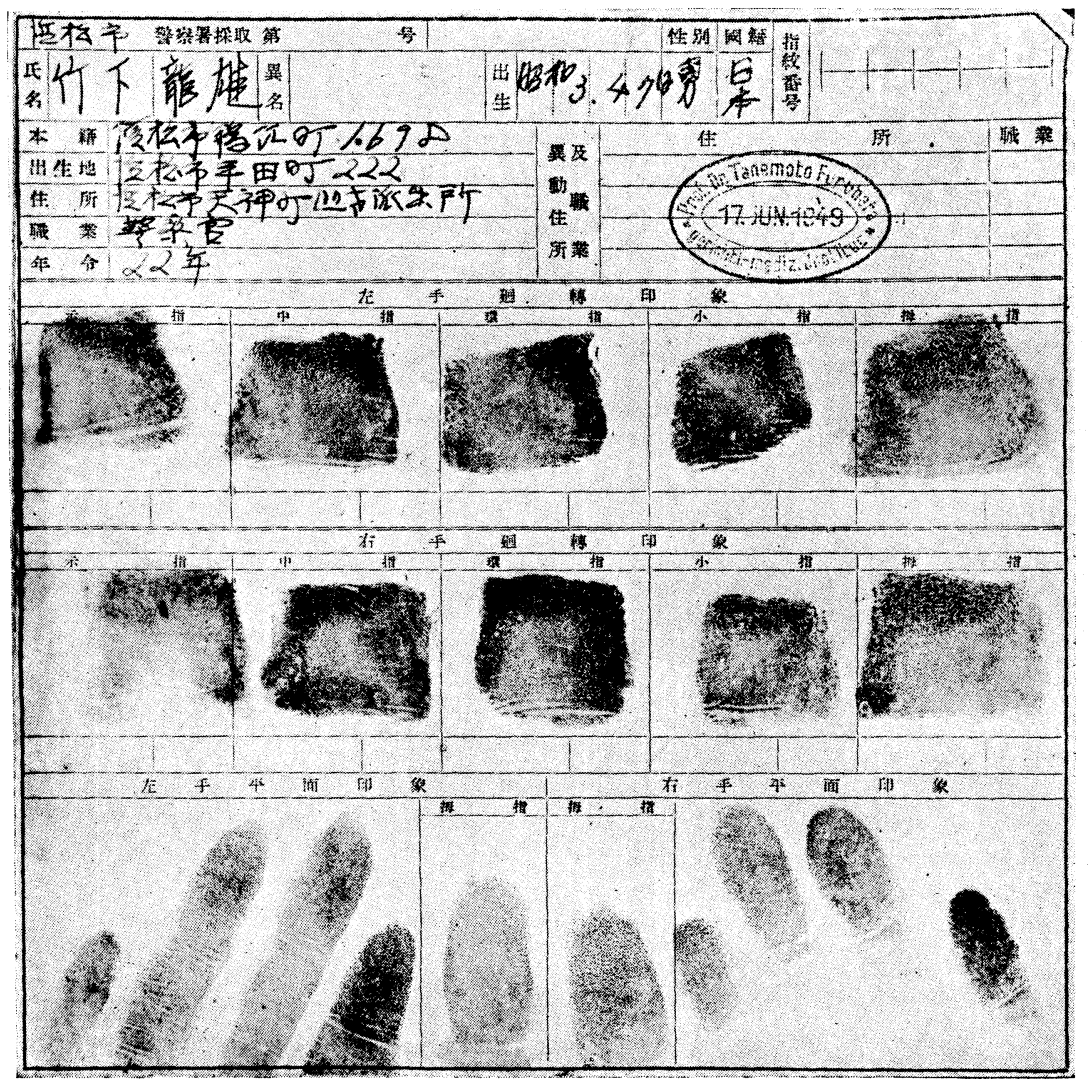

Fig. 1. Finger prints of the young policeman Tatsuo Takeshita. 


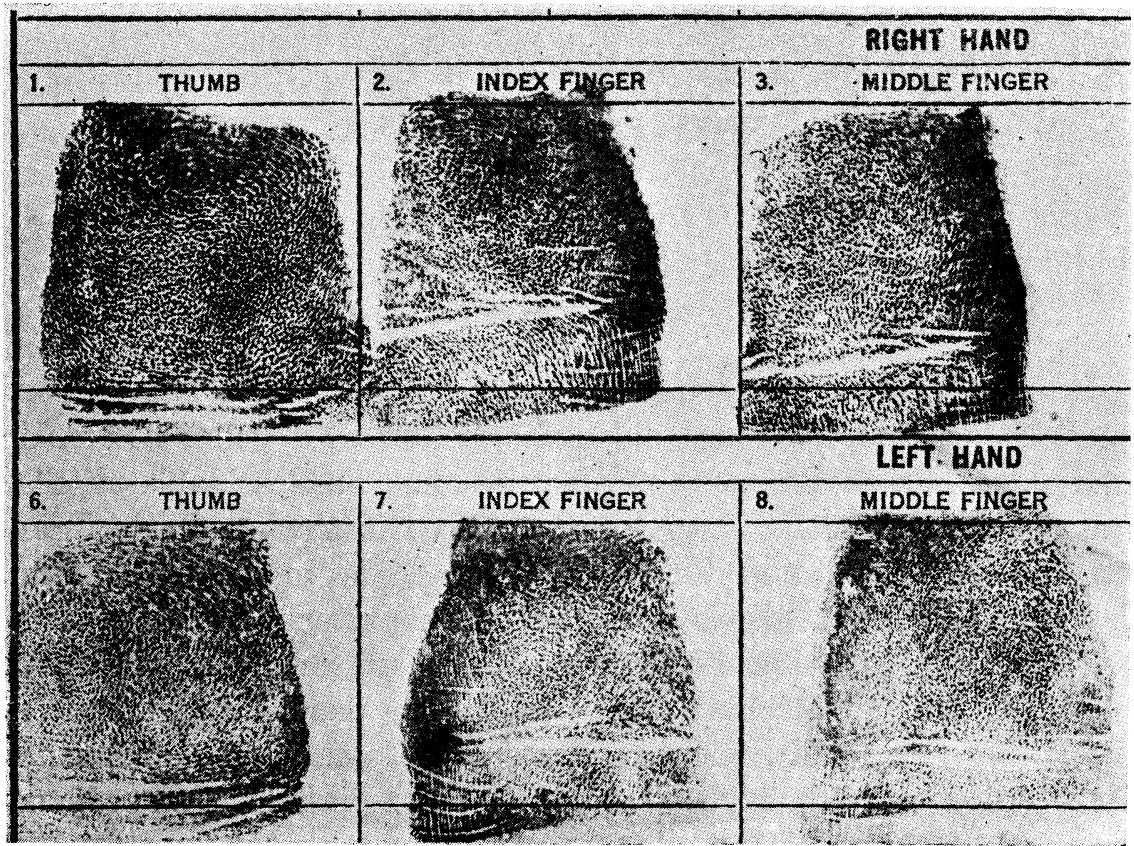

Fig. 2. Finger prints of the hands of Tatsuo Takeshita.

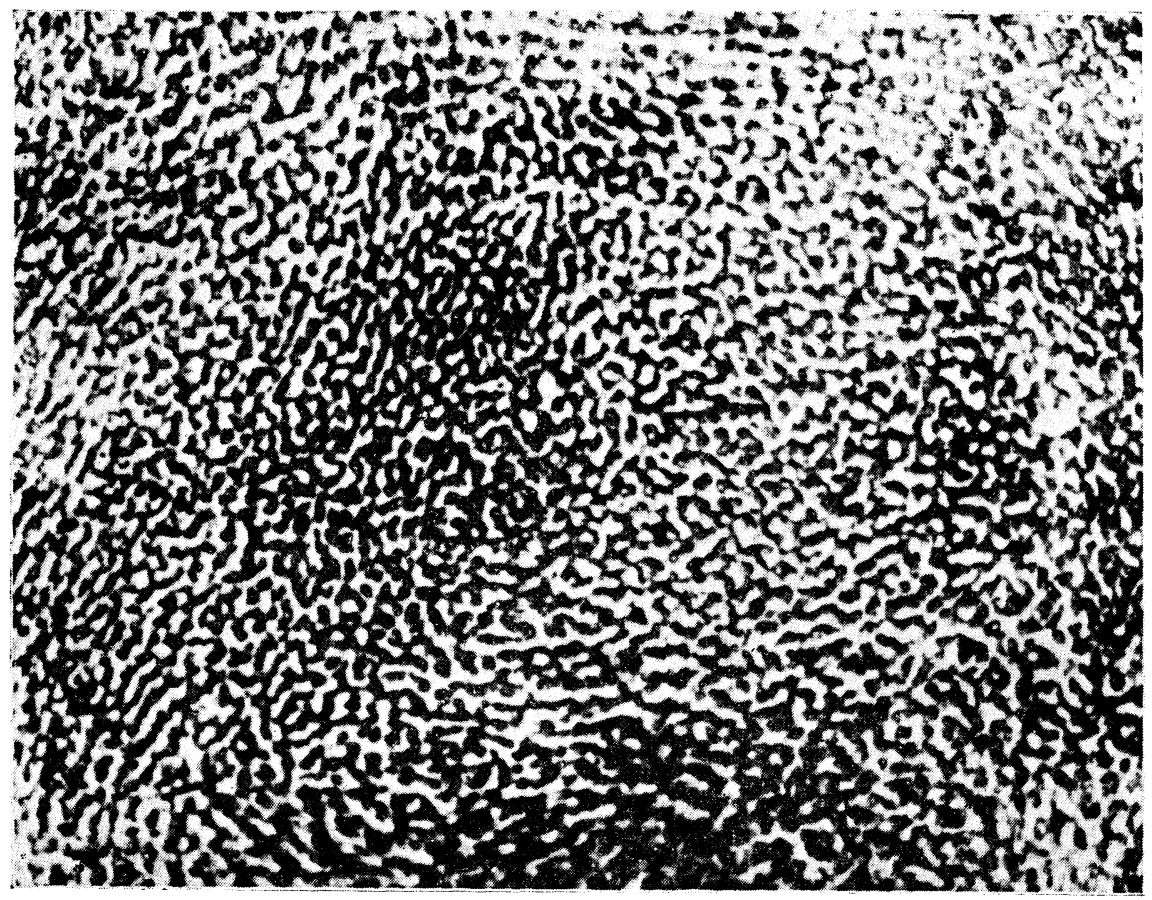

Fig. 3. Finger print of the right thumb (Enlarged). 
man. By histological examination of the excised skin part of his ring-finger, we can find no abnormal histological finding. The openings of the sweat glands are irregularly arranged and not in a line. But on the skin of his palms and soles we can not find papillar ridges as in an ordinary man.

By literature, Leonido Ribeiro (1934) in Rio De Janeiro reported that the finger prints are often transformed or disappear in a leper and Marion Carey (1942) reported on the unusual finger pattern. But it is considered very unusual that a healthy man has entirely no papillar ridge pattern on his ten fingers and ten toes.

In this connection I make an additional remark that the above case was reported by Lt. Col. C. H. Goddard in the Finger Print and Identification Magazine Vol. 31, No. 7 published in Jan. 1950.

\section{References.}

1) Leonido Ribeiro: A lepra é capaz de alterar os desenhos papillares das impressoes digitaes. 1934, 1-15.

2) Marion Carey: Pathological Dactyloscopy. Finger Print Magazine 1942, July : 5-18. 